\title{
Dietary electrolytes are related to mood
}

\author{
Susan J. Torres ${ }^{1 *}$, Caryl A. Nowson ${ }^{1}$ and Anthony Worsley ${ }^{2}$ \\ ${ }^{1}$ School of Exercise and Nutrition Sciences, Centre for Physical Activity and Nutrition, Deakin University, 221 Burwood Highway, \\ Burwood 3125, Australia \\ ${ }^{2}$ Victorian Health Promotion Foundation, PO Box 154, Carlton South 3053, Australia
}

(Received 20 August 2007 - Revised 13 February 2008 - Accepted 13 February 2008 - First published online 9 May 2008)

Dietary therapies are routinely recommended to reduce disease risk; however, there is concern they may adversely affect mood. We compared the effect on mood of a low-sodium, high-potassium diet (LNAHK) and a high-calcium diet (HC) with a moderate-sodium, high-potassium, high-calcium Dietary Approaches to Stop Hypertension (DASH)-type diet (OD). We also assessed the relationship between dietary electrolytes and cortisol, a stress hormone and marker of hypothalamic-pituitary-adrenal (HPA) axis activity. In a crossover design, subjects were randomized to two diets for 4 weeks, the OD and either LNAHK or HC, each preceded by a 2-week control diet (CD). Dietary compliance was assessed by $24 \mathrm{~h}$ urine collections. Mood was measured weekly by the Profile of Mood States (POMS). Saliva samples were collected to measure cortisol. The change in mood between the preceding CD and the test diet (LNAHK or HC) was compared with the change between the CD and OD. Of the thirty-eight women and fifty-six men (mean age 56.3 (SEM 9.8) years) that completed the OD, forty-three completed the LNAHK and forty-eight the HC. There was a greater improvement in depression, tension, vigour and the POMS global score for the LNAHK diet compared to OD $(P<0.05)$. Higher cortisol levels were weakly associated with greater vigour, lower fatigue, and higher levels of urinary potassium and magnesium $(r 0 \cdot 1-0 \cdot 2, P<0 \cdot 05$ for all). In conclusion, a LNAHK diet appeared to have a positive effect on overall mood.

Diet: Mood: Urinary electrolytes: Cortisol

Dietary recommendations to improve health and reduce disease risk are routinely made in health care settings. There is concern, however, that some dietary modifications, which can be burdensome, might adversely affect mood and psychological well-being. A low-fat diet administered over 4 weeks increased ratings of anger-hostility ${ }^{(1)}$. Restricted-energy diets for the treatment of overweight and obesity have been reported to increase fatigue and decrease vigour ${ }^{(2,3)}$ and increase ten$\operatorname{sion}^{(3)}$, which may be associated with feelings of deprivation and hunger. One study, however, did report a neutral effect on mood of an energy-restricted $\operatorname{diet}^{(4)}$, and a 12 -week lowfat diet improved depression and anxiety ${ }^{(5)}$. Hypertension is a well-established risk factor for $\mathrm{CHD}^{(6)}$, and the Dietary Approaches to Stop Hypertension (DASH) diet (a moderatesodium, high-potassium and high-calcium diet, high in fruits, vegetables and low-fat dairy products) is the recommended dietary pattern to reduce blood pressure $(\mathrm{BP})^{(7)}$. There is evidence from studies in rats that sodium depletion can induce depressive-like behaviours ${ }^{(8)}$. Therefore, the effect of changes in dietary electrolytes on mood in human subjects is an important consideration. The Trial of Antihypertensive Interventions and Management study found a low-sodium diet was associated with greater fatigue, when compared to a usual or weight-loss $\operatorname{diet}^{(9)}$. In contrast to this, a low-sodium diet for the treatment of hypertension significantly improved psychologic well-being scores when compared to a control group $^{(10)}$. Furthermore, the DASH diet not only resulted in a significant reduction in $\mathrm{BP}^{(11)}$, but also appeared to improve perceptions of health-related quality of life, which included measurements of vitality and mental health ${ }^{(12)}$.

Cortisol is an important steroid hormone in the regulation of normal physiology, and may be related to mood as it is a key hormone in the response to stress ${ }^{(13)}$. The secretion of cortisol, which is a marker of hypothalamic-pituitary-adrenal (HPA) axis activity, follows a diurnal pattern with peak levels following awakening and declining levels thereafter ${ }^{(14)}$. Dysregulation of the HPA axis has been associated with poor health, particularly with regards to mood states. Negative mood states including depression in men ${ }^{(15)}$, fatigue in women ${ }^{(16)}$, and stress in both men ${ }^{(17)}$ and pregnant women ${ }^{(18)}$ have been associated with higher levels of cortisol in the afternoon/ evening period. Conversely, 'burnout' as a result of chronic stress in men ${ }^{(17)}$ and post-traumatic stress disorder ${ }^{(19)}$ have been associated with lower levels of cortisol in the afternoon/ evening period. Considering the importance of the relationship between a normally functioning HPA axis and good health, recent research has reported that dietary factors may alter cortisol secretion. Some dietary patterns may have beneficial effects by reducing cortisol secretion, including lactovegetarian diets $^{(20)}$. A diet rich in the milk protein $\alpha$-lactalbumin provided

Abbreviations: AUC, area under the total response curve; BP, blood pressure; CD, control diet; DASH, Dietary Approaches to Stop Hypertension; HC, high-calcium; HPA, hypothalamic-pituitary-adrenal; LNAHK, low-sodium high-potassium; OD, DASH-type diet; POMS, Profile of Mood States.

* Corresponding author: Susan Torres, fax +61392446017, email sjtor@deakin.edu.au 
on $1 \mathrm{~d}$ reduced cortisol secretion and depressive feelings during stress ${ }^{(21)}$. However, some dietary patterns appear to have no effect on cortisol secretion including high-fat diets ${ }^{(22)}$, carbohydrate-restricted $\operatorname{diets}^{(23)}$ and a diet enriched with $\alpha$-lactalbumin ${ }^{(24)}$, or a trend for a rise in cortisol with a highprotein, low-carbohydrate diet ${ }^{(25)}$. It is possible that dietary electrolytes may alter cortisol secretion. A large reduction in dietary sodium intake from 200 to $20 \mathrm{mmol} / \mathrm{d}$ was found to decrease urinary cortisol excretion ${ }^{(26)}$. Increasing sodium intake from 40 to $320 \mathrm{mmol} / \mathrm{d}$ increased urinary cortisol excretion $^{(27)}$. Consumption of supplements over a $7 \mathrm{~d}$ period to neutralize endogenous acid production, which included potassium, was found to decrease morning plasma cortisol levels ${ }^{(28)}$.

The purpose of the present study was to determine if there were any differential effects on mood of a low-sodium, highpotassium (LNAHK) diet and a high-calcium (HC) diet compared to a moderate-sodium, high-potassium, high-calcium DASH-type diet (OD). An additional aim was to assess the relationship between dietary electrolytes (measured by urinary excretion), mood and salivary cortisol. This was part of a larger investigation examining the effects of dietary modification on BP in free-living individuals ${ }^{(29)}$.

\section{Methods}

All subjects provided written informed consent prior to starting the study, which was approved by the Deakin University Human Research Ethics Committee.

\section{Subjects}

Details of subject recruitment are reported elsewhere ${ }^{(29)}$. Subjects were eligible if they were greater than 25 years old and had a BP measured at the Centre by research staff (office BP) in the high/normal range $(\geq 120 \mathrm{mmHg}$ systolic $\mathrm{BP}$ or $\geq 80 \mathrm{mmHg}$ diastolic BP). Ninety-seven male and female subjects commenced the study.

\section{Study design}

This study utilized a randomized crossover design, which compared the difference in mood scores during each test diet with an immediately preceding control diet (CD) (Fig. 1). The CD was similar to the US DASH CD ${ }^{(11)}$. All subjects received two 4-week dietary interventions (one was the OD), each preceded by a 2 -week CD. Subjects were randomly allocated to one of four groups, which determined the order of test diets followed. In summary, all subjects completed the OD diet, approximately half followed the LNAHK diet and half the HC diet, and each of these test diets was preceded by a 2-week CD. Details of randomization are reported elsewhere ${ }^{(29)}$.

Every 2 weeks subjects attended the Centre or were visited by a researcher at their worksite for dietary counselling, and recording of weight and home BP. Mood data were collected weekly throughout the study (13 weeks). Subjects performed $24 \mathrm{~h}$ urine collections every 2 weeks to assess dietary compliance. The first morning urine of the designated collection day was discarded and then urine was collected for the next $24 \mathrm{~h}$. Saliva samples were collected at the end of each dietary period. Additionally, subjects were instructed to maintain their usual level of physical activity throughout the duration of the study.

\begin{tabular}{|c|c|c|c|c|}
\hline $\begin{array}{c}2 \\
\text { weeks }\end{array}$ & $\begin{array}{c}2 \\
\text { weeks }\end{array}$ & $\begin{array}{c}4 \\
\text { weeks }\end{array}$ & $\begin{array}{c}2 \\
\text { weeks }\end{array}$ & $\begin{array}{c}4 \\
\text { weeks }\end{array}$ \\
\hline Baseline & $\begin{array}{c}\text { Control } \\
\text { diet }\end{array}$ & Test diet & $\begin{array}{c}\text { Control } \\
\text { diet }\end{array}$ & Test diet \\
\hline \multirow[t]{3}{*}{ Mood } & $\begin{array}{l}\text { Mood } \\
\text { cortisol }\end{array}$ & $\begin{array}{l}\text { Mood } \\
\text { cortisol }\end{array}$ & $\begin{array}{l}\text { Mood } \\
\text { cortisol }\end{array}$ & $\begin{array}{l}\text { Mood } \\
\text { cortisol }\end{array}$ \\
\hline & $\boldsymbol{4}$ & 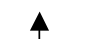 & $\boldsymbol{\Delta}$ & $\Delta$ \\
\hline & \multicolumn{2}{|c|}{$\Delta$ Mood } & \multicolumn{2}{|c|}{$\Delta$ Mood } \\
\hline
\end{tabular}

Fig. 1. Study design. The study was a randomized crossover design. Subjects were randomly allocated to one of four groups to determine the order of intervention. Group 1: diet 1, Dietary Approaches to Stop Hypertension (DASH)-type diet (OD); diet 2, low-sodium, high-potassium (LNAHK); Group 2: diet 1, LNAHK; diet 2, OD; Group 3: diet 1, OD; diet 2, high-calcium (HC); Group 4: diet 1, HC; diet 2, OD. Mood was measured weekly and the mean was calculated for each diet phase. Saliva samples were collected at the end of the control diet and test diet phases. The mean of two $24 \mathrm{~h}$ urine collections (during the last 3 weeks) was used for each test diet period and one for each control diet period. $\Delta$ Mood, change in mood.

Diets

The CD was low in potassium, magnesium and calcium. Subjects were also instructed to maintain their usual intake of dietary fat and sodium while following the CD. The OD diet was based on the US DASH ${ }^{(11)}$ and was high in potassium, magnesium and fibre; and low in sodium and saturated fat. The LNAHK diet differed from the OD diet in that it was lower in sodium and calcium. The HC diet was specifically high in calcium. Details of the dietary instruction and composition have been published previously ${ }^{(29)}$.

During the CD and all test diet periods, a maximum of four caffeine-containing drinks (e.g. cola drinks, coffee and tea) and two standard alcoholic drinks ( $10 \mathrm{~g}$ alcohol) were permitted daily.

\section{Anthropometry and blood pressure measurements}

Details on the methods used to measure home BP and pulse rate, weight, height and calculation of BMI $\left(\mathrm{kg} / \mathrm{m}^{2}\right)$ have been published previously ${ }^{(29)}$.

\section{Mood}

An abbreviated thirty-seven-item version of the Profile of Mood States (POMS) ${ }^{(30)}$ was used to assess participants' mood state. The thirty-seven-item POMS is designed to assess current and changes in mood states, and has been validated ${ }^{(31)}$. Each week, participants rated their mood state on five-point Likert scales $(0=$ not at all, $4=$ extremely) which best described how they had been feeling during the past week.

\section{Saliva samples}

Three saliva samples were collected using the Salivette sampling device (Sarstedt, Rommelsdorf, Germany) at the end of each dietary phase. Salivary cortisol is now an accepted, convenient method that is used to provide an indication of the variation of cortisol secretion throughout 
the day ${ }^{(32)}$. Salivary cortisol correlates with serum/plasma cortisol concentrations ${ }^{(32)}$ and is stable at room temperature for up to $7 \mathrm{~d}^{(33)}$. Subjects were requested to abstain from smoking; ingesting caffeine, alcohol, food and all fluids; and strenuous physical activity for $1 \mathrm{~h}$ before each saliva collection. A saliva sample was collected at approximately 12.00, 16.00 and 20.00 hours. All saliva samples were stored at room temperature and then spun at $2000 \mathrm{rpm}$ for $5 \mathrm{~min}$ within $5 \mathrm{~d}$ of collection, and then stored at $-80^{\circ} \mathrm{C}$ until assayed.

\section{Laboratory measurements}

Salivary cortisol was analysed with an enzyme immunoassay (Diagnostics Systems Laboratories Inc., TX, USA). Each sample was assayed in duplicate, and intra- and inter-assay variability was 13 and $7 \%$, respectively. Urinary electrolytes (24h) were assayed using a Hitachi 704 analyser (electrodes and reagents supplied by Boehringer Mannheim $\mathrm{GmbH}$ ).

\section{Statistical analysis}

Preliminary analyses. Scores for each person on each of the thirty-seven items of POMS were averaged across the 13 weeks of the study and then a principal components analysis with oblique rotation was performed ${ }^{(34)}$. Six factors had eigenvalues greater than 1 , but several items were loaded with similar strength across more than one factor, or loaded below 0.5 . Seven items were subsequently dropped from analyses. A principal components analysis with oblique rotation of the remaining thirty items resulted in simple structure. The thirty items explained $85.2 \%$ of the variance in mood. The following six factors emerged: Anger (furious, bitter, angry, annoyed, resentful, grouchy, peeved) (range 0-28); Confusion (unable to concentrate, forgetful, confused) (range 0-12); Depression (worthless, hopeless, helpless) (range 0-12); Fatigue (exhausted, fatigued, worn out, bushed, weary) (range 0-20); Tension (anxious, nervous, uneasy, on edge, tense, restless) (range 0-24); and Vigour (lively, energetic, vigorous, full of pep, active, cheerful) (range 0-24). In addition, the POMS global score (total mood disturbance) was used to obtain an overall measure of mood, and was calculated from the raw scores by subtracting the vigour score from the sum of the negative measures of mood and adding a constant of 100 to eliminate negative values (range $100-176)^{(4)}$.

With regards to the afternoon/evening cortisol samples (collected at approximately 12.00, 16.00 and 20.00 hours), 1091 samples were collected and of these $856(78 \%)$ were analysed and included in the final analysis. The remaining 256 samples were not assayed or included in the final analysis for the following reasons: (1) samples were missing; (2) no samples were available in the matching diet period; (3) there was a time difference of $\leq 2 \mathrm{~h}$ or $\geq 2 \mathrm{~h}$ from the indicated collection time.

Analysis. Statistical analysis was performed using the Statistical Product and Service Solutions software (SPSS version 12.0.1; SPSS Inc., Chicago, IL, USA) and SAS for Windows version 9.1 (SAS Institute Inc., Cary, NC, USA). Values are expressed as means and standard deviations when describing baseline characteristics, and means and standard errors of the mean were used for comparisons between groups.

The six mood factors used in the final analysis were based on the mean of two collections during the baseline and $\mathrm{CD}$ periods, and the mean of four collections during the test diet periods. For salivary cortisol levels during the afternoon/evening, which represented approximately an $8 \mathrm{~h}$ time period, the area under the total response curve (AUC) $\left(\mathrm{nmol} / \mathrm{l}\right.$ per $8 \mathrm{~h}$ ) was calculated using the trapezoid formula ${ }^{(35)}$. The mean collection time for all subjects was 08.14 (SD 0.43) hours. The mean of two $24 \mathrm{~h}$ urine collections taken in the last 3 weeks of the dietary intervention phase were used in the final analysis.

The three diet groups (OD, LNAHK and HC) were not independent. The weight, BP and urinary electrolyte data were both normally distributed and continuous. The difference between weight, BP and urinary electrolytes during the $\mathrm{CD}$ and diet period were analysed using paired Student's $t$ tests. Urinary electrolyte levels between the LNAHK and HC compared to the OD diet periods were assessed using Student's $t$ tests (same individuals). The mood data were both skewed and ordinal. The difference between mood factors during the $\mathrm{CD}$ and diet period was analysed using Wilcoxon signed ranks tests. The difference between the change in mood factors between the OD period and the LNAHK period, and the OD period and the HC diet period was determined using Wilcoxon signed ranks tests, and adjustments for multiple comparisons were made using Sharper Bonferroni procedures ${ }^{(36)}$. Associations between change in mood factors and change in BP were adjusted for repeated measurements (subject variables) using the GENMOD procedure with generalized estimating equations, before Pearson correlations were determined. Associations between mood factors, $24 \mathrm{~h}$ excretion of urinary metabolites and cortisol concentration (AUC) were adjusted for repeated measurements (both subject and diet phase variables) using the GENMOD procedure with generalized estimating equations methods, before their Pearson correlations were determined (significance was set at $P<0.01$ to minimize type 1 errors). Additionally, multivariate regression analysis was used to determine predictors of mood factors. $P<0.05$ was considered to be statistically significant unless otherwise indicated.

\section{Results}

\section{Subject characteristics}

Ninety-four subjects completed the OD diet period, forty-three completed the LNAHK diet period and forty-eight completed the HC diet period. There were more men than women who completed the study (Table 1). Of the thirty-eight women in the study, twelve (32\%) were pre-menopausal and twentysix $(68 \%)$ were post-menopausal. The mean BMI $\left(\mathrm{kg} / \mathrm{m}^{2}\right)$ for the study participants was within the overweight range $^{(37)}$ (Table 1). There were seven subjects $(7 \%)$ who indicated they had a mental health condition and/or were taking medications for a mental health condition, for example depression. At baseline, there was no difference in the POMS global score between males ( $n$ 56) and females (n 38) (108.1 (SEM 2.3) v. 110.7 (SEM 1.8); $P>0.05$ ); between premenopausal ( $n$ 12) and post-menopausal women ( $n$ 26) (108.0 (SEM 2.3) v. 115.8 (SEM 3.7); $P>0.05$ ); between subjects who indicated they had a mental health condition and/or were taking medication for a mental health condition $(n 7)$ and those without a mental health condition ( $n$ 87) 
Table 1. Baseline characteristics of study participants $(n 94) \dagger$

(Mean values and standard deviations)

\begin{tabular}{|c|c|c|}
\hline & Mean & SD \\
\hline No. of women/men & $38 / 56$ & \\
\hline Age (years) & 55.6 & \\
\hline Weight (kg) & 84.0 & $13 \cdot 3$ \\
\hline BMI $\left(\mathrm{kg} / \mathrm{m}^{2}\right)$ & $29 \cdot 0$ & 3.8 \\
\hline Home SBP $(\mathrm{mmHg})$ & $129 \cdot 4$ & $11 \cdot 3$ \\
\hline Home DBP $(\mathrm{mmHg})$ & $80 \cdot 6$ & $8 \cdot 6$ \\
\hline Home pulse rate $(\mathrm{bpm})$ & $67 \cdot 3$ & \\
\hline \multicolumn{3}{|l|}{ POMS } \\
\hline Anger (range 0-28) & 4.4 & 4. \\
\hline Confusion (range $0-12$ ) & $2 \cdot 2$ & 1 \\
\hline Depression (range 0-12) & 0.8 & 1 \\
\hline Fatigue (range $0-20$ ) & $6 \cdot 1$ & 4. \\
\hline Tension (range 0-24) & $5 \cdot 3$ & 4 \\
\hline Vigour (range 0-20) & $10 \cdot 0$ & 4 \\
\hline Global score (range $100-176$ ) & $109 \cdot 1$ & $15 \cdot 1$ \\
\hline Urinary sodium $(\mathrm{mmol} / \mathrm{d})$ & 149.9 & 49. \\
\hline Urinary potassium $(\mathrm{mmol} / \mathrm{d})$ & 77.5 & 24.5 \\
\hline Urinary sodium/potassium & $2 \cdot 1$ & 0.9 \\
\hline Urinary calcium $(\mathrm{mmol} / \mathrm{d})$ & 3.6 & $2 \cdot 1$ \\
\hline Urinary magnesium $(\mathrm{mmol} / \mathrm{d})$ & 4.4 & 1.4 \\
\hline
\end{tabular}

DBP, diastolic blood pressure; POMS, Profile of Mood States; SBP, systolic blood pressure.

†For details of procedures, see Methods.

(127.1 (SEM 11.5) v. 107.7 (SEM 1.3); $P>0.05$ ). Comparing males and females during the first $\mathrm{CD}$ period, there were no differences in cortisol levels (AUC) (2.02 (SEM 0.16) v. 1.87 (SEM 0.18$) \mathrm{nmol} / \mathrm{l}$ per $8 \mathrm{~h} ; P>0.05$ ). Combining the four dietary test periods, mean salivary cortisol at approximately 12.00 , 16.00 and 20.00 hours was 7.63 (SEM 0.21), 6.05 (SEM 0.24) and 3.43 (SEM 0.16) nmol/l, respectively.

Differences between baseline and first control diet periods, and between first and second control diet periods

Comparing baseline with the first CD period, there was a trend for a lower POMS global score during the first $\mathrm{CD}$ period (109.1 (SEM 1.6) v. $108 \cdot 0$ (SEM 1.6); $P=0 \cdot 076$ ). Comparing the two CD periods, the POMS global score was significantly lower in the second CD period (107.9 (SEM 1.6) v. 103.3 (SEM 1.3$) ; P<0.05$ ) and urinary potassium was 5.3 (SEM 2.4) $\mathrm{mmol} / \mathrm{d}$ higher $(P<0 \cdot 05)$.

\section{Body weight and blood pressure}

Assessing the change in weight between the three test diets and $C D$ period (test diet $-C D$ ) there was no change during the OD diet period ( $+0 \cdot 1$ (SEM $0 \cdot 1) \mathrm{kg} ; P>0 \cdot 05)$, a significant reduction during the LNAHK diet period ( -0.4 (SEM 0.2) $\mathrm{kg}$; $P<0.05)$ and a significant increase during the $\mathrm{HC}$ diet period $(+0.9$ (SEM 0.1) kg; $P<0.05)$. When compared to the OD diet group, there was a greater increase in weight during the $\mathrm{HC}$ diet period (same individuals) $(+0.7$ (SEM 0.2$) \mathrm{kg} ; P<0.05)$.

The changes in BP (systolic BP/diastolic BP) between the dietary phases and the $\mathrm{CD}$ (test diet $-\mathrm{CD}$ ) were: $\mathrm{OD}$ : -1.68 (SEM 0.5$) /-0.4 \quad$ SEM 0.3$) \quad \mathrm{mmHg} \quad(P<0.001$ and $P>0.05$, respectively); LNAHK: -4.4 (SEM 0.8 ) $/-2 \cdot 0$ (SEM $0.6) \mathrm{mmHg}$ (both $P<0.001$ ); HD: $+0.6 \quad($ SEM 0.4 )/ +0.3 (SEM 0.3) mmHg (both $P>0.05$ ).

\section{Urinary electrolytes}

During the OD diet period compared to the CD period, there was a decrease in sodium of 28.1 (SEM 6.5) $\mathrm{mmol} / \mathrm{d}$ $(P<0.05)$ and an even greater reduction of 77.4 (SEM 9.4) $\mathrm{mmol} / \mathrm{d}(P<0.05)$ during the LNAHK diet period. There was a substantial and comparable increase in urinary potassium, 34.0 (SEM 3.0) $\mathrm{mmol} / \mathrm{d}(P<0.05)$ and 35.4 (SEM 4.5) $\mathrm{mmol} / \mathrm{d}(P<0.05)$ for the OD and LNAHK diet periods compared to the CD period, respectively. Urinary magnesium excretion increased in all three diet periods when compared to the CD period (OD: 0.8 (SEM 0.2) $\mathrm{mmol} / \mathrm{d}$; LNAHK: 4.8 (SEM 0.2) $\mathrm{mmol} / \mathrm{d}$; HC: 4.5 (SEM 0.2) $\mathrm{mmol} / \mathrm{d}$; $P<0.05$ for all). In the same individuals during the LNAHK diet period $v$. the OD diet period, urinary sodium excretion was lower (59.0 (SEM 5.4) v. 116.6 (SEM 7.3) $\mathrm{mmol} / \mathrm{d} ; P<0.05)$ and urinary calcium excretion was lower (2.6 (SEM 0.3) v. $3.6($ SEM 0.4$) \mathrm{mmol} / \mathrm{d} ; P<0.05)$. In the same individuals during the $\mathrm{HC}$ diet period $v$. the OD diet period, urinary sodium excretion was higher (151.6 (SEM 7.3) v. $118.0($ SEM 7.7) $\mathrm{mmol} / \mathrm{d} ; P<0.05)$ and urinary calcium excretion was higher (4.6 (SEM 0.4) v. 3.7 (SEM 0.3) $\mathrm{mmol} / \mathrm{d}$; $P<0 \cdot 05)$.

\section{Effects of dietary modifications on mood}

Assessing the change in mood between the three test diets and $\mathrm{CD}$ period (test diet $-\mathrm{CD}$ ) there was a significant reduction in the POMS global score for the LNAHK and HC diets; however, these were no longer significant when adjustments were made for multiple comparisons (LNAHK: -3.9 (SEM 1.8), $P=0.019$; HC: -2.5 (SEM 1.0), $P=0.037$ ). There was no significant change in the POMS global score during the OD diet compared with the CD $(-1.5$ (SEM $0 \cdot 8), P=0 \cdot 102)$. Individuals who completed the LNAHK diet had a greater reduction in depression, tension and the POMS global score, and an increase in vigour when compared to their response with the OD diet (Table 2). There were no significant differences in the change in mood scores for the HC compared to the OD diet groups (Table 2).

Table 2. The difference in the changes in mood ( $\Delta$; test diet - control diet) between the low-sodium, high-potassium diet (LNAHK) or highcalcium diet $(\mathrm{HC})$ diet periods compared with the Dietary Approaches to Stop Hypertension (DASH)-type diet (OD) period $†$

(Mean values with their standard errors)

\begin{tabular}{|c|c|c|c|c|}
\hline \multirow[b]{2}{*}{ POMS } & \multicolumn{2}{|c|}{$\begin{array}{l}\Delta \text { LNAHK }-\Delta \\
\text { OD }(n 43)\end{array}$} & \multicolumn{2}{|c|}{$\begin{array}{l}\Delta \mathrm{HC}-\Delta \mathrm{OD} \\
(n 48)\end{array}$} \\
\hline & Mean & SEM & Mean & SEM \\
\hline Anger (range 0-28) & $-1 \cdot 1$ & 0.5 & -0.3 & 0.6 \\
\hline Confusion (range $0-12$ ) & -0.4 & 0.2 & 0.4 & 0.2 \\
\hline Depression (range 0-12) & $-0.5^{\star}$ & 0.2 & 0.1 & 0.2 \\
\hline Fatigue (range 0-20) & -0.6 & 0.6 & -0.1 & 0.6 \\
\hline Tension (range 0-24) & $-1 \cdot 6^{\star}$ & 0.5 & 0.4 & 0.5 \\
\hline Vigour (range 0-20) & $1 \cdot 2^{*}$ & 0.6 & $-1 \cdot 1$ & 0.6 \\
\hline Global score (range 100-176) & $-5 \cdot 4^{*}$ & $2 \cdot 1$ & $1 \cdot 6$ & $1 \cdot 6$ \\
\hline
\end{tabular}

POMS, Profile of Mood States.

Mean value was significantly different from that compared with the change during the OD period (Wilcoxon signed ranks test): ${ }^{*} P<0.05$ after Sharper Bonferron correction.

†For details of procedures, see Methods. 
There were no significant relationships between the changes in the POMS global score, BP, weight and cortisol (data not shown).

\section{Twenty-four hour urinary electrolyte excretion, mood and cortisol concentration}

Sodium intake was associated with anger and vigour, such that those with lower urinary sodium excretion had lower levels of anger and vigour (Table 3). Higher urinary excretion of potassium was associated with lower fatigue, and higher magnesium excretion was associated with higher vigour. In addition, urinary excretion of potassium and magnesium were positively associated with levels of cortisol. Higher levels of urinary calcium excretion were associated with lower levels of fatigue and the POMS global score. A lower sodium/potassium ratio was associated with lower levels of anger and depression. Greater vigour, lower fatigue and lower POMS global score, which are all indicative of better mood, were all associated with a higher level of salivary cortisol. Multivariate regression analysis indicated that urinary predictors of fatigue included urinary potassium $(\beta$ -0.03 (SE 0.01)) and urinary calcium ( $\beta-0.36$ (SE 0.09)) and that this combination explained $60 \%$ of the variance $\left(R^{2} 0.060 ; P<0.001\right)$. For vigour, a model which included both urinary sodium $(\beta \quad 0.02$ (SE 0.01$))$ and urinary magnesium $(\beta 0.82$ (SE 0.15$)$ ) explained $84 \%$ of the variance $\left(R^{2} 0.084 ; P<0.001\right)$.

\section{Discussion}

In a population of community-dwelling individuals participating in a dietary intervention study to reduce BP, we found that three diets did not have a deleterious effect on mood. Furthermore, the results of the present study indicate a dietary pattern that is low in sodium and high in potassium appeared to improve mood. The effect of dietary change on mood and psychological well-being is an important consideration, particularly when dietary therapies are routinely recommended to the general public for the treatment of conditions such as hypertension $^{(7)}$. Participation in a dietary intervention programme which involves strict adherence to dietary guidelines, numerous clinical measurements and questionnaires, and regular visits to the study centre, could impact negatively on an individual's mood. The results from the present study do not appear to support this, as we found no evidence for a deleterious effect on mood, which is similar to findings from other studies ${ }^{(4,38)}$.

We found the LNAHK diet in comparison to the OD diet resulted in small but significant improvements in depression, tension and vigour, and the global mood score. This was also confirmed by significant associations between urinary electrolytes and mood, where a lower sodium and higher potassium intake was associated with better mood. The present findings contrast with recent literature that suggests dietary sodium reduction may have deleterious effects on mood. The Trial of Antihypertensive Interventions and Management study found reducing sodium increased fatigue but did not alter levels of depression ${ }^{(9)}$. There is evidence from studies in rats that sodium depletion can induce depressive-like behaviours $^{(8)}$, although in the present study sodium levels on the LNAHK diet were reduced rather than depleted. Sodium reduction can activate the renin-angiotensin system which increases aldosterone ${ }^{(39)}$, and higher levels of aldosterone have been reported in patients with clinical depression as compared to controls ${ }^{(40)}$. In a Cochrane review, a urinary sodium reduction to $20 \mathrm{mmol} / \mathrm{d}$ corresponded with a 5-6-fold increase in aldosterone ${ }^{(39)}$. In the present study, urinary sodium levels on the LNAHK diet were above this level, approximately $60 \mathrm{mmol} / \mathrm{d}$, which may not be low enough to stimulate a clinically significant rise in aldosterone. Furthermore, we did not find an increase in depression POMS scores (deterioration of mood) in those following the LNAHK diet. An alternative explanation for the improvement in depression when subjects followed the LNAHK diet might be due to an increase in dietary magnesium. Low serum magnesium levels have been reported in depressed individuals with diabetes ${ }^{(41)}$ and hospital patients $^{(42)}$, but not postpartum women ${ }^{(43)}$. Furthermore, magnesium supplementation can be an effective treatment of depression ${ }^{(44)}$. It should also be acknowledged that in contrast to the improvement in vigour on the LNAHK diet, a higher urinary sodium excretion was associated with higher vigour, when examined across all dietary patterns. However, in a model that included both urinary sodium and urinary magnesium, this was found to be a significant predictor of vigour. Dietary magnesium is an essential mineral and has a key role

Table 3. Correlations between $24 \mathrm{~h}$ excretion of urinary electrolytes, mood factors and salivary cortisol $\dagger$

\begin{tabular}{|c|c|c|c|c|c|c|}
\hline & $\begin{array}{l}\text { Sodium } \\
(\mathrm{mmol} / \mathrm{d})\end{array}$ & $\begin{array}{l}\text { Potassium } \\
(\mathrm{mmol} / \mathrm{d})\end{array}$ & Sodium/potassium & $\begin{array}{l}\text { Calcium } \\
(\mathrm{mmol} / \mathrm{d})\end{array}$ & $\begin{array}{l}\text { Magnesium } \\
(\mathrm{mmol} / \mathrm{d})\end{array}$ & $\begin{array}{l}\text { Salivary cortisol } \\
\text { (AUC nmol// per } 8 \mathrm{~h} \text { ) }\end{array}$ \\
\hline \multicolumn{7}{|l|}{ POMS } \\
\hline Anger & $0.129^{\star \star}$ & -0.040 & $0.139^{\star * *}$ & -0.041 & 0.037 & -0.085 \\
\hline Confusion & 0.108 & -0.023 & 0.107 & -0.058 & -0.024 & -0.043 \\
\hline Depression & 0.090 & -0.105 & $0.125^{\star * *}$ & -0.114 & -0.099 & 0.030 \\
\hline Fatigue & -0.044 & $-0 \cdot 169^{\star \star \star}$ & 0.078 & $-0 \cdot 205^{\star \star \star}$ & -0.043 & $-0 \cdot 197^{\star \star \star}$ \\
\hline Tension & 0.034 & -0.027 & 0.050 & -0.100 & 0.025 & -0.029 \\
\hline Vigour & $0.154^{\star \star \star}$ & 0.027 & 0.077 & 0.053 & $0 \cdot 256^{\star \star \star}$ & $0.174^{\star \star \star}$ \\
\hline Global score & -0.001 & -0.094 & 0.074 & $-0.140^{\star \star \star}$ & -0.102 & $-0 \cdot 154^{\star \star \star}$ \\
\hline Salivary cortisol (AUC nmol// per $8 \mathrm{~h}$ ) & 0.051 & $0.181^{\star \star *}$ & -0.099 & 0.049 & $0.134^{\star \star *}$ & \\
\hline
\end{tabular}

AUC, area under the curve; POMS, Profile of Mood States.

Values were significantly different from those of the control group: ${ }^{\star \star} P<0.01,{ }^{\star \star \star} P<0.001(P<0.01$ was considered to be statistically significant).

†Data are from all three diet groups combined and from each phase of the study (baseline, control diet, test diet 1, control diet, test diet 2). Associations were adjusted for repeated measurements (both subject and diet phase variables) using the GENMOD procedure with generalized estimating equations methods, prior to assessment of Pearson correlations. 
in energy metabolism, and deficiency of magnesium can lead to a myriad of symptoms including muscular weakness and lethargy ${ }^{(45)}$. Therefore, the higher levels of vigour may be attributed to the role that magnesium has in energy metabolism. Further studies are required to determine the robustness of these findings and to dissect out possible relationships between overall mood and dietary sodium and magnesium. In the present study, higher urinary calcium excretion was associated with better mood including lower fatigue and the global mood score. Unlike urinary sodium and potassium, urinary calcium is not directly related to dietary intake, and is likely to be influenced by genetic factors ${ }^{(46)}$.

It is possible other factors could have contributed to the improvements in mood. There was an improvement in mood from the first to the second $\mathrm{CD}$ period, which could have been due to regular contact with motivating research staff. However, we found that there was an improvement in mood on the LNAHK diet compared to the OD, which is unlikely to be due to generalized participation in a dietary study. It should be noted that subjects were not blinded to any BP reductions, and this knowledge could have contributed to a positive effect on mood, particularly as the greatest BP reductions were seen on the LNAHK diet, although there was no relationship between the change in BP and change in mood. Other factors such as reduction in body weight can have adverse effects on mood by increasing hunger and feelings of perceived deprivation ${ }^{(47)}$. In the present study, weight changes were small and we found no relationship between the change in weight and the change in mood.

The subjects enrolled in the present study comprised of healthy individuals who were predominantly free of mental health issues, which is evident from the low baseline values for negative mood states. As a consequence, the improvements in mood were also small. During the LNAHK diet compared to the OD diet, tension decreased by 1.6 units on the POMS scale, which was similar to a reduction in tension-anxiety after following a low-fat diet ${ }^{(5)}$. These small improvements in mood may not be clinically relevant to an individual, but could be important at a population level, since these dietary modifications are routinely made to lower BP.

Overall, salivary cortisol concentrations during the afternoon/evening period were comparable to levels reported in other studies ${ }^{(17,48,49)}$ and were consistent with a normally functioning HPA axis ${ }^{(17)}$. In the present study we found small but significant correlations between mood and cortisol, such that greater vigour and lower fatigue were associated with higher cortisol levels. This is supported by a study which found that acute administration of $35 \mathrm{mg}$ cortisol (a relatively large dose) decreased fatigue, although fatigue decreased by only a small amount, approximately 1 unit on the POMS scale ${ }^{(50)}$. However, the present findings are contrary to results from other studies, where negative mood states, including depression, fatigue and stress, have been associated with higher cortisol levels ${ }^{(15-17)}$. It is important to highlight difficulties when comparing studies due to the differences in analytical approaches used to express cortisol levels (e.g. area under the curve, comparison of absolute values, change scores). In the present study, it is likely that positive mood states (greater vigour, lower fatigue) were associated with a normally functioning HPA axis and therefore normal levels of cortisol. Similarly, within our popu- lation group, urinary potassium and magnesium excretion was positively associated with an apparently normally functioning HPA axis. In contrast to this, one study reported that acute administration of potassium $(200 \mathrm{mmol} / \mathrm{d})$ did not affect cortisol secretion ${ }^{(51)}$. We found no relationship between urinary sodium and cortisol in the present population group. A reduction from 200 to $20 \mathrm{mmol} / \mathrm{d}$ has been found to decrease urinary cortisol excretion ${ }^{(26)}$, but in the present study urinary sodium was three times higher than this on the LNAHK diet. The findings from the present study are of interest; however, further studies are required to understand the relationship between dietary electrolytes and cortisol secretion.

The strengths of the present study include a crossover design which enabled us to test the same individual following two diets, and to examine the effect of the diets at different time-points during the study. Moreover, the numbers of subjects tested in each diet group is comparable to other studies which have investigated the effect of dietary modifications on mood ${ }^{(5)}$. Correlation coefficients between mood variables and $24 \mathrm{~h}$ excretion of urinary metabolites were modest but consistent, and were also supported by similar changes in mood following dietary intervention. A possible limitation of the present study design is that subjects were asked to complete the mood questionnaire weekly over the 13-week study. Participants may have become familiar with the instrument and selected similar results, which would diminish the capacity to detect changes in mood over the study. Despite this, we did find an improvement in mood during the LNAHK diet. Furthermore, the generalizability of findings from the present study is limited to a population of generally healthy men and women participating in a short-term dietary intervention study.

In conclusion, dietary patterns that can assist in lowering blood pressure do not seem to have a deleterious effect on mood. In particular, a low-sodium, high-potassium diet appears to have an overall positive effect on general mood state, but the potential inter-relationship between mood and dietary electrolytes requires further investigation.

\section{Acknowledgements}

This research study was supported by a grant (DU10426) from Dairy Australia. The sponsoring organization was not involved in the design, analyses or reporting of the results. S. T. was the recipient of a PhD scholarship from Dairy Australia. The authors wish to acknowledge Claire Margerison (M Nutr Diet) and Michelle K. Jorna (BAppSc (Hmvt)) for conducting the diet programme. We also thank Professor Sing Kai Lo for his advice regarding the statistical analysis of these results. None of the authors have any personal or financial conflicts in this work.

\section{References}

1. Wells AS, Read NW, Laugharne JD \& Ahluwalia NS (1998) Alterations in mood after changing to a low-fat diet. $\mathrm{Br} J$ Nutr 79, 23-30.

2. Buffenstein R, Karklin A \& Driver HS (2000) Beneficial physiological and performance responses to a month of restricted energy intake in healthy overweight women. Physiol Behav 68, 439-444. 
3. Degoutte F, Jouanel P, Begue RJ, Colombier M, Lac G, Pequignot JM \& Filaire E (2006) Food restriction, performance, biochemical, psychological, and endocrine changes in judo athletes. Int J Sports Med 27, 9-18.

4. Nieman DC, Custer WF, Butterworth DE, Utter AC \& Henson DA (2000) Psychological response to exercise training and/or energy restriction in obese women. J Psychosom Res 48, 23-29.

5. Wardle J, Rogers P, Judd P, Taylor MA, Rapoport L, Green M \& Nicholson Perry K (2000) Randomized trial of the effects of cholesterol-lowering dietary treatment on psychological function. Am J Med 108, 547-553.

6. Bennett SA \& Magnus P (1994) Trends in cardiovascular risk factors in Australia. Med J Aust 161, 519-527.

7. Chobanian AV, Bakris GL, Black HR, et al. (2003) The Seventh Report of the Joint National Committee on Prevention, Detection, Evaluation, and Treatment of High Blood Pressure: the JNC 7 report. JAMA 289, 2560-2572.

8. Grippo AJ, Moffitt JA, Beltz TG \& Johnson AK (2006) Reduced hedonic behavior and altered cardiovascular function induced by mild sodium depletion in rats. Behav Neurosci 120, $1133-1143$

9. Wassertheil-Smoller S, Blaufox MD, Oberman A, Davis BR, Swencionis C, Knerr MO, Hawkins CM \& Langford HG (1991) Effect of antihypertensives on sexual function and quality of life: the TAIM Study. Ann Intern Med 114, 613-620.

10. Whelton PK, Kumanyika SK, Cook NR, et al. (1997) Efficacy of nonpharmacologic interventions in adults with high-normal blood pressure: results from phase 1 of the Trials of Hypertension Prevention. Trials of Hypertension Prevention Collaborative Research Group. Am J Clin Nutr 65, 652S-660S.

11. Appel LJ, Moore TM, Obarzanek E, et al. (1997) A clinical trial of the effects of dietary patterns on blood pressure. $N$ Engl $J$ Med 336, 1117-1124.

12. Plaisted CS, Lin PH, Ard JD, McClure ML \& Svetkey LP (1999) The effects of dietary patterns on quality of life: a substudy of the Dietary Approaches to Stop Hypertension trial. J Am Diet Assoc 99, S84-S89.

13. Folkow B (1997) Physiological aspects of the 'defence' and 'defeat' reactions. Acta Physiol Scand Suppl 640, 34-37.

14. Sherwood L (2001) Human Physiology from Cells to Systems, 4th ed. Pacific Grove, CA: Brooks/Cole.

15. van Eck M, Berkhof H, Nicolson N \& Sulon J (1996) The effects of perceived stress, traits, mood states, and stressful daily events on salivary cortisol. Psychosom Med 58, 447-458.

16. Bower JE, Ganz PA, Dickerson SS, Petersen L, Aziz N \& Fahey JL (2005) Diurnal cortisol rhythm and fatigue in breast cancer survivors. Psychoneuroendocrinology 30, 92-100.

17. Bjorntorp P, Holm G, Rosmond R \& Folkow B (2000) Hypertension and the metabolic syndrome: closely related central origin? Blood Press 9, 71-82.

18. Obel C, Hedegaard M, Henriksen TB, Secher NJ, Olsen J \& Levine S (2005) Stress and salivary cortisol during pregnancy. Psychoneuroendocrinology 30, 647-656.

19. Yehuda R, Golier JA \& Kaufman S (2005) Circadian rhythm of salivary cortisol in Holocaust survivors with and without PTSD. Am J Psychiatry 162, 998-1000.

20. Remer T, Pietrzik K \& Manz F (1998) Short-term impact of a lactovegetarian diet on adrenocortical activity and adrenal androgens. J Clin Endocrinol Metab 83, 2132-2137.

21. Markus CR, Olivier B, Panhuysen GE, et al. (2000) The bovine protein alpha-lactalbumin increases the plasma ratio of tryptophan to the other large neutral amino acids, and in vulnerable subjects raises brain serotonin activity, reduces cortisol concentration, and improves mood under stress. Am J Clin Nutr 71, 1536- 1544 .

22. Volek JS, Gomez AL, Love DM, Avery NG, Sharman MJ \& Kraemer WJ (2001) Effects of a high-fat diet on postabsorptive and postprandial testosterone responses to a fat-rich meal. Metabolism 50, 1351-1355.

23. Volek JS, Sharman MJ, Love DM, Avery NG, Gomez AL, Scheett TP \& Kraemer WJ (2002) Body composition and hormonal responses to a carbohydrate-restricted diet. Metabolism 51, 864-870

24. Merens W, Booij L, Markus R, Zitman FG, Onkenhout W \& Van der Does AJ (2005) The effects of a diet enriched with alpha-lactalbumin on mood and cortisol response in unmedicated recovered depressed subjects and controls. Br J Nutr 94, $415-422$.

25. Nuttall FQ \& Gannon MC (2006) The metabolic response to a high-protein, low-carbohydrate diet in men with type 2 diabetes mellitus. Metabolism 55, 243-251.

26. Lewicka S, Nowicki M \& Vecsei P (1998) Effect of sodium restriction on urinary excretion of cortisol and its metabolites in humans. Steroids 63, 401-405.

27. Wambach G, Bleienheuft C \& Bonner G (1986) Sodium loading raises urinary cortisol in man. $J$ Endocrinol Invest $\mathbf{9}$, 257-259.

28. Maurer M, Riesen W, Muser J, Hulter HN \& Krapf R (2003) Neutralization of Western diet inhibits bone resorption independently of $\mathrm{K}$ intake and reduces cortisol secretion in humans. Am J Physiol Renal Physiol 284, F32-F40.

29. Nowson CA, Worsley A, Margerison C, Jorna MK, Frame AG, Torres SJ \& Godfrey SJ (2004) Blood pressure response to dietary modifications in free-living individuals. $J$ Nutr 134, 2322-2329.

30. Shacham S (1983) A shortened version of the Profile of Mood States. J Pers Assess 47, 305-306.

31. Baker F, Denniston M, Zabora J, Polland A \& Dudley WN (2002) A POMS short form for cancer patients: psychometric and structural evaluation. Psychooncology 11, 273-281.

32. Kirschbaum C \& Hellhammer DH (1994) Salivary cortisol in psychoneuroendocrine research: recent developments and applications. Psychoneuroendocrinology 19, 313-333.

33. Groschl M, Wagner R, Rauh M \& Dorr HG (2001) Stability of salivary steroids: the influences of storage, food and dental care. Steroids 66, 737-741.

34. Kim J \& Mueller C (1994) Introduction to factor analysis: what it is and how to do it. In Factor Analysis and Related Techniques, pp. 1-69 [M Lewis-Beck, editor]. London: Sage Publications.

35. Pruessner JC, Kirschbaum C, Meinlschmid G \& Hellhammer DH (2003) Two formulas for computation of the area under the curve represent measures of total hormone concentration versus time-dependent change. Psychoneuroendocrinology 28, 916-931.

36. Hochberg Y \& Benjamini Y (1990) More powerful procedures for multiple significance testing. Stat Med 9, 811-818.

37. World Health Organisation (2000), Obesity: Preventing and Managing the Global Epidemic, Technical Report Series no. 894. Geneva: WHO.

38. Booij L, Merens W, Markus CR \& Van der Does AJ (2006) Diet rich in alpha-lactalbumin improves memory in unmedicated recovered depressed patients and matched controls. J Psychopharmacol 20, 526-535.

39. Jurgens G \& Graudal NA (2004) Effects of low sodium diet versus high sodium diet on blood pressure, renin, aldosterone, catecholamines, cholesterols, and triglyceride. Cochrane Database Syst Rev CD004022.

40. Emanuele E, Geroldi D, Minoretti P, Coen E \& Politi P (2005) Increased plasma aldosterone in patients with clinical depression. Arch Med Res 36, 544-548.

41. Barragan-Rodriguez L, Rodriguez-Moran M \& GuerreroRomero F (2007) Depressive symptoms and hypomagnesemia in older diabetic subjects. Arch Med Res 38, 752-756. 
42. Hashizume N \& Mori M (1990) An analysis of hypermagnesemia and hypomagnesemia. Jpn J Med 29, 368-372.

43. Wojcik J, Dudek D, Schlegel-Zawadzka M, et al. (2006) Antepartum/postpartum depressive symptoms and serum zinc and magnesium levels. Pharmacol Rep 58, 571-576.

44. Eby GA \& Eby KL (2006) Rapid recovery from major depression using magnesium treatment. Med Hypotheses 67, 362-370.

45. National Health and Medical Research Council (2006) Nutrient Reference Values for Australia and New Zealand. Including Recommended Dietary Intakes. Canberra: NHMRC.

46. Hunter DJ, Lange M, Snieder H, MacGregor AJ, Swaminathan R, Thakker RV \& Spector TD (2002) Genetic contribution to renal function and electrolyte balance: a twin study. Clin Sci (Lond) 103, 259-265.
47. McClernon FJ, Yancy WS Jr, Eberstein JA, Atkins RC \& Westman EC (2007) The effects of a low-carbohydrate ketogenic diet and a low-fat diet on mood, hunger, and other selfreported symptoms. Obesity 15, 182-187.

48. Lai JC, Evans PD, Ng SH, et al. (2005) Optimism, positive affectivity, and salivary cortisol. Br J Health Psychol 10, 467-484.

49. Nicolson NA \& van Diest R (2000) Salivary cortisol patterns in vital exhaustion. J Psychosom Res 49, 335-342.

50. Tops M, van Peer JM, Wijers AA \& Korf J (2006) Acute cortisol administration reduces subjective fatigue in healthy women. Psychophysiology 43, 653-656.

51. Dluhy RG, Axelrod L, Underwood RH \& Williams GH (1972) Studies of the control of plasma aldosterone concentration in normal man. II. Effect of dietary potassium and acute potassium infusion. J Clin Invest 51, 1950-1957. 